\title{
An Assessment of Diagnostic Equipment Utilization in a Tertiary Healthcare Setup: A Key to Economical Patient Management
}

\author{
${ }^{1}$ Poonam Chaudhary, ${ }^{2}$ Pankaj Kaul
}

\section{ABSTRACT}

Equipment utilization management is the evaluation of the medical equipment necessity, appropriateness, and efficiency of the use in the healthcare services or procedures. The investment on an equipment is said to be a good one if it shows a utilization coefficient of $50 \%$ or above.

The study was descriptive observational in nature and was conducted in the Histopathology Department, PGIMER, Chandigarh. The data for the entire year of 2012 was collected by studying various records of the department including purchase files, inventory registers, log books and service records of medical equipments.

The results indicated that the Utilization Coefficients of various diagnostic equipments in the department of Histopathology, PGIMER, Chandigarh for the year 2012 were in the order of $58.1,62.1$ and $60.4 \%$ for high cost, medium cost and low cost equipments respectively.

On an average, the utilization coefficient of medical equipments under study (Year 2012) of the Histopathology Department, PGIMER, Chandigarh, was found to be $60.2 \%$ (above $50 \%$ ). This figure reflects that the budget spent on average medical diagnostic equipment in this department is very much justifiable. The study also showed that the cost incurred on various cost categories of diagnostic equipments, i.e. the low, medium and high cost equipments was also equally important.

Keywords: Low, Medium and high cost diagnostic equipments, Utilization coefficient, Break down, Equipment down time and daily work load.

How to cite this article: Chaudhary P, Kaul P. An Assessment of Diagnostic Equipment Utilization in a Tertiary Healthcare Setup: A Key to Economical Patient Management. Int J Res Foundation Hosp Healthc Adm 2014;2(2):111-116.

Source of support: Nil

Conflict of interest: None declared

${ }^{1}$ Senior Medical Laboratory Technologist, ${ }^{2}$ Tutor Technologist

${ }^{1}$ Department of Anatomy, Government Medical College and Hospital, Chandigarh, India

${ }^{2}$ Department of Histopathology, Postgraduate Institute of Medical Education and Research, Chandigarh, India

Corresponding Author: Poonam Chaudhary, Senior Medical Laboratory Technologist, Department of Anatomy, Government Medical College and Hospital, Sector 32, Chandigarh-160030 India, e-mail: purnima_chaudhary@rediffmail.com

\section{INTRODUCTION}

Hospitals have undergone a quantum change in concept and care provisioning from ancient days to present era. The information explosion and technological advances have revolutionized the medical care. The sophistication in the medical field has led to the development of specialized care centers in an attempt to provide high quality care. Modern medical technology has contributed immensely in improving the quality of healthcare and state of health profile of nations. The advancement has been mainly due to: improved diagnostic facilities; sophisticated equipments, and spectacular progress in development in surgical procedures. ${ }^{1}$

The introduction of state of art technology has resulted in metamorphic changes in diagnostic and therapeutic modalities in patient care activities. This has led to enhancement of quality of life and decreased morbidity and mortality rates. ${ }^{1}$

Medical equipments contribute to almost 40 to $50 \%$ costs in a tertiary hospital setup. The medical equipment though cutting edge at the time of purchase poses threat of inevitable obsolescence within 6 to 7 years of installation. This problem is compounded by the fact that most of such equipments are imported and very few local reputed manufacturers exist in India. This leads to putting higher treatment costs and further to lesser competitive edges and low utilization rates resulting in undesired operating margins. ${ }^{2}$

The availability and utilization of various healthcare equipments at all levels in the health system for effective and efficient service delivery, was also emphasized in the Alma-Ata declaration at the International Conference on Primary Health Care in 1978, which was later included into the strategy of Health for all by 2000 AD. ${ }^{3}$

Medical equipment is an integral part of the physical infrastructure of a healthcare setup. It is an important means of providing various services to the people. So, in a way it can be said that these equipments are of utmost importance and have become a necessity in almost all activities whether diagnostic, therapeutic, or supportive in nature. ${ }^{3}$

Many costly medical equipments are lying in the hospitals which are either never installed or are out of order for want of spares or proper maintenance. These types of 
happenings are very common and most of the big government hospitals are plagued with this problem, which not only gives bad publicity to the hospital administration but also leads to wastage of scarcely available resources of the country. Proper planning of medical equipment in a hospital will not only economize on resources but will also result in availability of maximum equipment in functional state all the time. ${ }^{4}$

Most of the states and other organizations in India have laid down rules and regulations for the procurement of equipments and other supplies in the hospitals. The basic rationale behind all these rules, regulations and procedures is to maximize the value of the money invested in the purchase of equipment. $^{5}$

It should be the earnest endeavor of the management and the users to optimize the equipment utilization to obtain maximum returns for the capital invested. In an era of costintensive medical care, every equipment being installed in healthcare institutions need to be fully and properly utilized.

An optimum utilization of equipment will result in as follows:

- Optimum patient handling and rapid turnover.

- Minimum possible cost of healthcare.

- Quality patient care and satisfaction.

Utilization essentially means the use of the equipment to the full potential. ${ }^{5}$

As of now for the smooth functioning of any healthcare facility that is from primary health center to a tertiary care institute effective management as well as maintenance play a major part. ${ }^{6}$

\section{AIMS AND OBJECTIVES}

1. To enumerate the various diagnostic equipments used in random in various sections of the department.

2. To categorize them into the low, medium and high cost equipments based on their procurement cost.

3. To find the utilization coefficient of these equipments individually during the year 2012 (January 2012 to December 2012) for 12 months.

\section{MATERIALS AND METHODS}

The study was conducted in the Histopathology Department, PGIMER, Chandigarh. PGIMER, Chandigarh is a medical education and research institute. It has educational, medical research and training facilities for students of various categories other than imparting tertiary healthcare services in North India. The tools and techniques applied in the study are presented in Table 1.

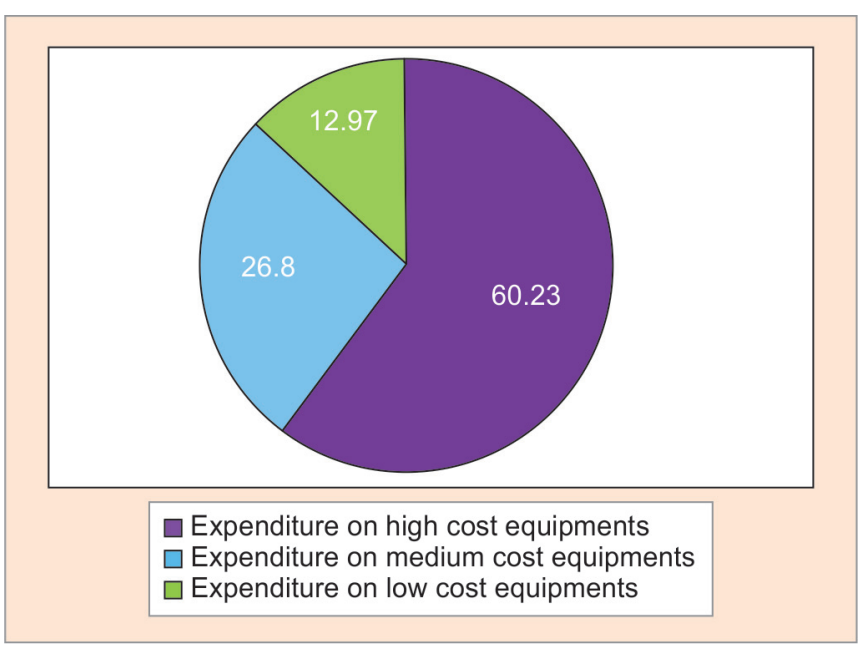

Graph 1: Percentage of expenditure on medical equipments

\section{RESULTS AND ANALYSIS}

\section{Analysis of Objective 1}

To enumerate the various diagnostic instruments used for random in the various sections of the department, a final list of 50 medical diagnostic equipments were selected for the study as presented in Table 2 .

There are mainly ten sections of the Department of Histopathology equipped with sophisticated medical diagnostic equipments according to the requirement of laboratory investigations. An average number of five equipments was selected from each section for the study.

\section{Analysis of Objective 2}

This section analyses the cost categorization and the percentage of expenditure incurred on these medical diagnostic equipments (Table 3 and Graph 1).

Based on the procurement cost, these medical diagnostic equipments were categorized into the low, medium and high cost equipments as presented in Table 3. For this purpose, the inventory and stock registers of the department were studied for the purchase orders of the equipments under study and their procurement costs were recorded. A final list of 30 medical equipments of different cost categories used for various techniques/purposes was prepared. These included 10 each of low, medium and high cost medical diagnostic equipments.

On analyzing the cost of these medical equipments, it was also observed that most of the equipments were of foreign origin and their procurement costs were available as per the respective foreign currency and hence they were converted into Indian currency, i.e. rupees to make the study simple and comparable.

On analyzing the data, it was observed that out of total expenditure of ₹ 4,64,87,345/-, 60.23\% (₹ 2,79,99,328/-) 
Table 1: Tools and techniques employed

\begin{tabular}{|c|c|}
\hline Purpose/Objective & Preliminary analysis \\
\hline Tools and techniques used & $\begin{array}{l}\text { Observation methods (study of records mentioned in log books, inventory/stock register of each medical } \\
\text { equipment under study) } \\
\text { Frequencies charts } \\
\text { Tabulation presentations } \\
\text { Pie charts }\end{array}$ \\
\hline Purpose/Objective no. 1 & To enumerate the various diagnostic equipments in different sections of the department. \\
\hline Tools and techniques used & $\begin{array}{l}\text { For this objective, four-step methodology was followed } \\
\text { Step 1: A complete list of all medical equipments used in the various sections of the department was } \\
\text { prepared. } \\
\text { Step 2: These were arranged as per their locations, i.e. various sections/labs of the department. } \\
\text { Step 3: Major diagnostic equipments from each section were selected by stratified random sampling } \\
\text { method. } \\
\text { Step 4: A total no. of } 50 \text { medical diagnostic equipments were selected for the study. }\end{array}$ \\
\hline Purpose/Objective no. 2 & To categorize them into the low, medium and high cost equipments based on their procurement cost. \\
\hline Tools and techniques used & $\begin{array}{l}\text { All the medical diagnostic equipments under study were categorized into three as per their procurement } \\
\text { cost as follows: } \\
\text { Low cost (Procurement cost less than } 5 \text { Lakhs) } \\
\text { Medium cost (Procurement cost falling between } 5 \text { and } 10 \text { Lakhs) } \\
\text { High cost (Procurement cost more than } 10 \text { Lakhs) }\end{array}$ \\
\hline Purpose/Objective no. 3 & $\begin{array}{l}\text { To find the utilization coefficient of these equipments individually during the year } 2012 \text { (January } 2012 \text { to } \\
\text { December 2012) for } 12 \text { months. }\end{array}$ \\
\hline Tools and techniques used & $\begin{array}{l}\text { Utilization coefficient was calculated using the following formula } \\
\text { Utilization coefficient }=\left(A^{*} B / C^{*} D\right)^{*} 100 \\
\text { Here, } \\
\text { 'A' the no. of days the medical equipment was actually used during the year } 2012 \text {. } \\
\text { For this, time period of the equipment down time was calculated and deducted from total working days } \\
\text { ('C'). } \\
\text { 'B' the no. of hours the equipment was actually used for a working day (average time taken by a } \\
\text { procedure on that equipment, * average no. of procedures performed in a working day). } \\
\text { Time taken for each procedure was asked and daily work load status was observed from the log books } \\
\text { of all the months of } 2012 \text {. The technologists were also enquired as to the uses/functions of the medical } \\
\text { diagnostic equipments under study. } \\
\text { ' } C \text { ' the no. of days the medical equipment could have been available (if there was no down time and the } \\
\text { equipment was put in working order). For this, PGIMER Calendar of the year } 2012 \text { was taken to find out } \\
\text { the total no. of working days as follows: } \\
\text { Total no. of days in } 2012=366 \text { ( } 2012 \text { being the leap year) } \\
\text { Total no. of sundays in } 2012=53 \\
\text { Total no. of gazetted holidays }=17 \\
\text { Total no. of OPD holidays }=11 \\
\text { Hence, total no. of working days were }=366-(53+17+11)=285 \text { days } \\
\text { So, 'C' was taken as } 285 \text { days for all the calculations. } \\
\text { ' } D \text { ' the no. of hours the medical diagnostic equipment could have been available in a working day } \\
\text { (if there was no equipment down time and the equipment was put in working order). } \\
\text { There were total } 233 \text { full working days (Monday to Friday; working timings } 9 \text { am to } 5 \text { pm and } 1 \text { hour } \\
\text { lunch break) and } 52 \text { half working days (Saturdays). } \\
\text { Total working hours }=\left(233^{*} 7\right)+\left(52^{*} 4\right)=(1631+208)=1839 \text { hours } \\
\text { Hence, average total working hours in a day was } 6.45 \text { hours }(1839 / 285) \text {. } \\
\text { So, ' } D \text { ' was taken as } 6.45 \text { working hours on daily basis for the calculation of utilization coefficient of } \\
\text { medical equipments. }\end{array}$ \\
\hline
\end{tabular}

was spent on high cost medical equipments, $26.8 \%$ (₹ $1,24,58,608 /$ ) was spent on medium cost equipments and the remaining $12.97 \%$ (₹ $60,29,409 /-$ ) was spent on the low cost medical equipments (Graph 1).

\section{Analysis of Objective 3}

The utilization coefficient of these medical diagnostic equipments were calculated individually for the year 2012 (January 2012 to December 2012) as per the formula stated in the methodology and is presented in Table 4.
Results of the above calculations were based on the criteria that if the utilization coefficient was less than $50 \%$, it was considered to be under-utilized and hence not a good investment and vice versa. However, life-saving equipments cannot be subjected to this kind of assessment.

\section{Percentage Utilization Coefficient of Medical Diagnostic Equipments}

The average percentage of utilization coefficient of different cost categories of medical diagnostic equipments is presented in Graphs 2 to 4. 
Table 2: Selection of medical diagnostic equipments section wise

\begin{tabular}{cll}
\hline Sl. no. & $\begin{array}{l}\text { Name of the departmental section/lab } \\
\text { (location of equipment) }\end{array}$ & $\begin{array}{l}\text { Quantity of medical diagnostic equipments selected for the } \\
\text { assessment of equipment utilization coefficient }\end{array}$ \\
\hline 1. & EM Lab & 01 \\
2. & Grossing lab & 05 \\
3. & Processing lab & 06 \\
4. & Microtomy lab & 06 \\
5. & Staining lab & 06 \\
6. & Immunohistochemistry lab & 04 \\
7. & Molecular lab & 05 \\
8. & Reporting lab & 08 \\
9. & EM processing lab & 05 \\
10. & Cryo/Frozen lab & 04 \\
\hline
\end{tabular}

Table 3: Expenditure spent on medical diagnostic equipments

\begin{tabular}{|c|c|c|c|c|c|c|}
\hline $\begin{array}{l}\text { SI. } \\
\text { no. }\end{array}$ & Name of medical equipment & $\begin{array}{l}\text { Department section/lab } \\
\text { (location of equipment) }\end{array}$ & $\begin{array}{l}\text { Procurement } \\
\text { cost per unit } \\
\text { in ₹ }\end{array}$ & $\begin{array}{l}\text { Cost cate- } \\
\text { gory low/ } \\
\text { medium/high }\end{array}$ & Qty. & $\begin{array}{l}\text { Total } \\
\text { procurement } \\
\text { cost in ₹ }\end{array}$ \\
\hline 1. & Transmission electron microscope & Electron microscope lab & $94,52,570$ & High & 01 & $94,52,570$ \\
\hline 2. & Thermo-shandon work station & Grossing lab & $11,22,000$ & High & 02 & $22,44,000$ \\
\hline 3. & Autopsy saw with HEPA bone dust collector & Grossing lab & $1,14,000$ & Low & 01 & $1,14,000$ \\
\hline 4. & Bone saw & Grossing lab & $5,73,800$ & Medium & 02 & $11,47,600$ \\
\hline 5. & $\begin{array}{l}\text { Automated tissue processor with fume } \\
\text { exhaust system }\end{array}$ & Processing lab & $9,40,929$ & Medium & 02 & $18,81,858$ \\
\hline 6. & $\begin{array}{l}\text { Rapid multifunctional microwave tissue } \\
\text { processor }\end{array}$ & Processing lab & $11,12,162$ & High & 01 & $11,12,162$ \\
\hline 7. & Embedding consol system & Processing lab & $2,27,000$ & Low & 02 & $4,54,000$ \\
\hline 8. & Fully enclosed tissue processor & Processing lab & $18,10,500$ & High & 01 & $18,10,500$ \\
\hline 9. & Rotary microtome & Microtomy lab & $6,53,112$ & Medium & 02 & $13,06,224$ \\
\hline 10. & Automatic microtome knife sharpener & Microtomy lab & $5,57,000$ & Medium & 02 & $11,14,000$ \\
\hline 11. & Automated microtome & Microtomy lab & $6,60,700$ & Medium & 02 & $13,21,400$ \\
\hline 12. & Autostainer & Staining lab & $10,53,000$ & High & 02 & $21,06,000$ \\
\hline 13. & Binocular research microscope & Staining lab & $3,56,440$ & Low & 04 & $14,25,760$ \\
\hline 14. & Automated immunostainer & Immunohistochemistry lab & $13,41,000$ & High & 01 & $13,41,000$ \\
\hline 15. & Antigen retrieval system decloaking chamber & Immunohistochemistry lab & $1,22,700$ & Low & 01 & $1,22,700$ \\
\hline 16. & Cold centrifuge & Immunohistochemistry lab & $3,74,563$ & Low & 02 & $7,49,126$ \\
\hline 17. & PCR machine with microfuge & Molecular lab & $4,46,600$ & Low & 02 & $8,93,200$ \\
\hline 18. & In situ hybridizer & Molecular lab & $4,81,442$ & Low & 01 & $4,81,442$ \\
\hline 19. & Gel documentation system & Molecular lab & $3,68,410$ & Low & 02 & $7,36,820$ \\
\hline 20. & Trinocular research microscope & Reporting lab & $3,90,000$ & Low & 01 & $3,90,000$ \\
\hline 21. & $\begin{array}{l}\text { Binocular research microscope with dual } \\
\text { viewing attachments }\end{array}$ & Reporting lab & $7,36,925$ & Medium & 02 & $14,73,850$ \\
\hline 22. & $\begin{array}{l}\text { Binocular research microscope } \\
\text { (ten header) }\end{array}$ & Reporting lab & $7,85,580$ & Medium & 02 & $15,71,160$ \\
\hline 23. & $\begin{array}{l}\text { Image analyzer fully automatic for DMRB } \\
\text { microscope }\end{array}$ & Reporting lab & $6,78,500$ & Medium & 01 & $6,78,500$ \\
\hline 24. & $\begin{array}{l}\text { Binocular research microscope for } \\
\text { transmitted light with photomicrography } \\
\text { attachment camera }\end{array}$ & Reporting lab & $17,80,399$ & High & 02 & $29,11,800$ \\
\hline 25. & $\begin{array}{l}\text { Digital imaging system for TEM } 906 \\
\text { consisting of CCD camera }\end{array}$ & Em processing lab & $19,54,560$ & High & 01 & $19,54,560$ \\
\hline 26. & Ultramicrotome and accessories & Em processing lab & $29,11,800$ & High & 01 & $29,11,800$ \\
\hline 27. & EM automated tissue processor & Em processing lab & $9,40,929$ & Medium & 01 & $9,40,929$ \\
\hline 28. & Diamond knife & Em processing lab & $5,11,662$ & Medium & 02 & $10,23,324$ \\
\hline 29. & Ultra low deep freezer & Cryo/frozen lab & $3,31,840$ & Low & 02 & $6,63,680$ \\
\hline 30. & Cryostat with UV disinfection system & Cryo/frozen lab & $10,76,690$ & High & 02 & $21,53,380$ \\
\hline
\end{tabular}


The average utilization coefficient of high cost medical equipments is $58.10 \%$ (Graph 2), for medium cost medical equipments is $62.10 \%$ (Graph 3 ) and that of low cost medical equipments is $60.40 \%$ (Graph 4 ).

\section{DISCUSSION}

The hospital spends a heavy sum of money on the procurement of state of the art equipment every year as per the needs and demands stated by the various departments of the hospital. Most of them have to be imported from foreign countries. Thus efficient utilization of such equipments is a major area of concern and also formed the basis of this study.

Planning and acquisition of medical equipments is a continuous process. Decision-makers are seldom trained or have the awareness of modern technology. These persons may not be responsible for its eventual operation and maintenance. There is a lack of coordination among agencies involved in various processes, from demand generation to procurement, finance and maintenance. Investment and recurring costs are nonsustainable. Equipment selection is not done as per the morbidity pattern or skills available to make the best use of the equipment but rather for prestige, craze for the latest and the best. If a hospital does not have a systematic purchase and maintenance plan for the medical equipments, it can lead to high cost, inadequate and improper utilization of the equipment. So, it has become mandatory to become the cost conscious and to be assertive of the cost benefits. Cost reduction is needed to be effected without affecting the quality and effectiveness of the services. Moreover, the medical equipments have applications only for the patients and have an impact on human lives and therefore, need to be dealt with in quite a different manner as compared to the other industries. It is imperative to assess its operative functionality and utilization by equipment audit, maintenance and repair. Hospital and clinical administrators are also faced with the expectation for return on investment that meets accounting guidelines and financial pressures.

Table 4: Utilization coefficient of medical equipments under study (Year 2012)

\begin{tabular}{|c|c|c|c|c|}
\hline $\begin{array}{ll}\text { S. } \\
\text { No. }\end{array}$ & Name of medical equipment & Department section/lab & $\begin{array}{l}\text { Cost category } \\
\text { low/medium/high }\end{array}$ & $\begin{array}{l}\text { Utilization } \\
\text { coefficient (\%) }\end{array}$ \\
\hline 1. & Transmission electron microscope & Electron microscope lab & High & 69.8 \\
\hline 2. & Thermo-Shandon work station & Grossing lab & High & 74.8 \\
\hline 3. & Autopsy saw with HEPA bone dust collector & Grossing lab & Low & 52.7 \\
\hline 4. & Bone saw & Grossing lab & Medium & 54.3 \\
\hline 5. & Automated tissue processor with fume exhaust system & Processing lab & Medium & 55.6 \\
\hline 6. & Rapid multifunctional microwave tissue processor & Processing lab & High & 55.8 \\
\hline 7. & Embedding consol system & Processing lab & Low & 75.3 \\
\hline 8. & Fully enclosed tissue processor & Processing lab & High & 61.0 \\
\hline 9. & Rotary microtome & Microtomy lab & Medium & 83.6 \\
\hline 10. & Automatic microtome knife sharpener & Microtomy lab & Medium & 31.0 \\
\hline 11. & Automated microtome & Microtomy lab & Medium & 54.3 \\
\hline 12. & Autostainer & Staining lab & High & 77.8 \\
\hline 13. & Binocular research microscope & Staining lab & Low & 50.0 \\
\hline 14. & Automated immunostainer & Immunohistochemistry lab & High & 40.0 \\
\hline 15. & Antigen retrieval system decloaking chamber & Immunohistochemistry lab & Low & 54.3 \\
\hline 16. & Cold centrifuge & Immunohistochemistry lab & Low & 47.7 \\
\hline 17. & PCR machine with microfuge & Molecular lab & Low & 70.0 \\
\hline 18. & In situ hybridizer & Molecular lab & Low & 43.4 \\
\hline 19. & Gel documentation system & Molecular lab & Low & 36.6 \\
\hline 20. & Trinocular research microscope & Reporting lab & Low & 74.4 \\
\hline 21. & $\begin{array}{l}\text { Binocular research microscope with dual viewing } \\
\text { attachments }\end{array}$ & Reporting lab & Medium & 77.5 \\
\hline 22. & Binocular research microscope (Ten header) & Reporting lab & Medium & 85.3 \\
\hline 23. & Image analyzer fully automatic for existing DMRB microscope & Reporting lab & Medium & 34.1 \\
\hline 24. & $\begin{array}{l}\text { Binocular research microscope for transmitted light with } \\
\text { photomicrography camera }\end{array}$ & Reporting lab & High & 35.6 \\
\hline 25. & Digital imaging system for TEM 906 consisting of CCD camera & Em processing lab & High & 62.0 \\
\hline 26. & Ultramicrotome and accessories & Em processing lab & High & 52.7 \\
\hline 27. & Em automated tissue processor & Em processing lab & Medium & 93.0 \\
\hline 28. & Diamond knife & Em processing lab & Medium & 52.7 \\
\hline 29. & Ultra low deep freezer & Cryo lab & Low & 100 \\
\hline 30. & Cryostat with UV disinfection system & Cryo lab & High & 51.2 \\
\hline
\end{tabular}




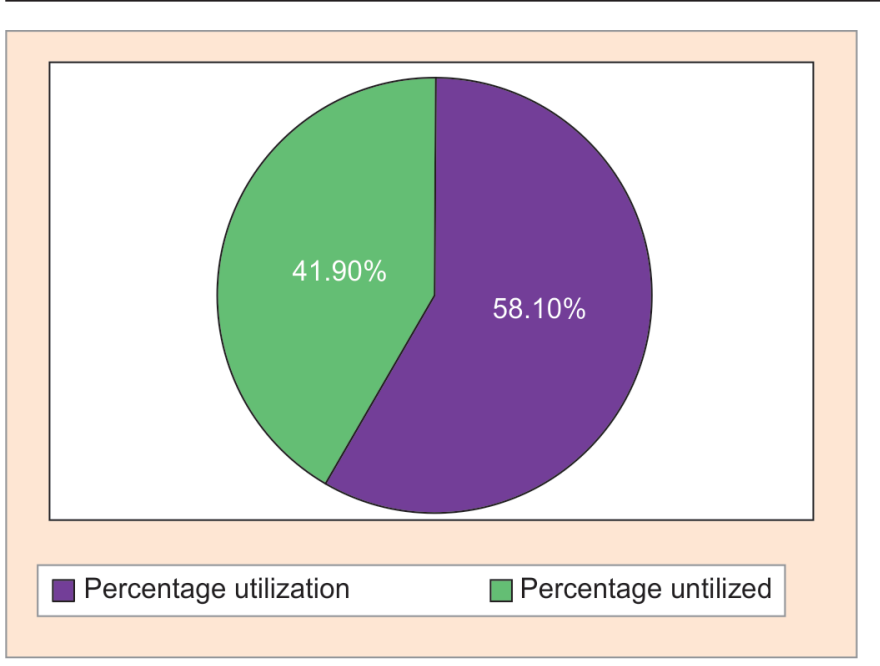

Graph 2: Average utilization coefficients of high cost medical equipments

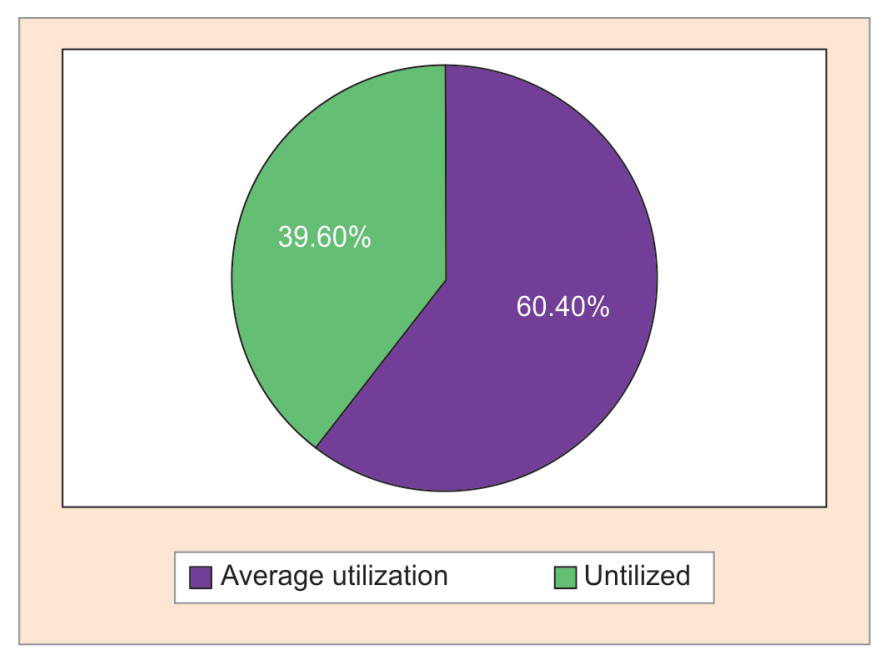

Graph 4: Average utilization coefficients of low cost medical equipments

In addition to the above mentioned bottlenecks, the hospital is a matrix organization and it definitely increases the challenges faced by the hospital administrators right from the time the equipment is procured to its optimum utilization.

\section{CONCLUSION}

The high cost medical equipments showed an average utilization coefficient of $58.1 \%$, medium cost categories equipment showed $62.1 \%$ and that of low cost categories was $60.4 \%$. Thus, on an average the utilization coefficient of medical equipments under study (Year 2012) of the department of histopathology, PGIMER, Chandigarh was found to be $60.2 \%$.

On an average, the utilization coefficient of medical equipments under study (Year 2012) of the Department of histopathology, PGIMER, Chandigarh, was found to be

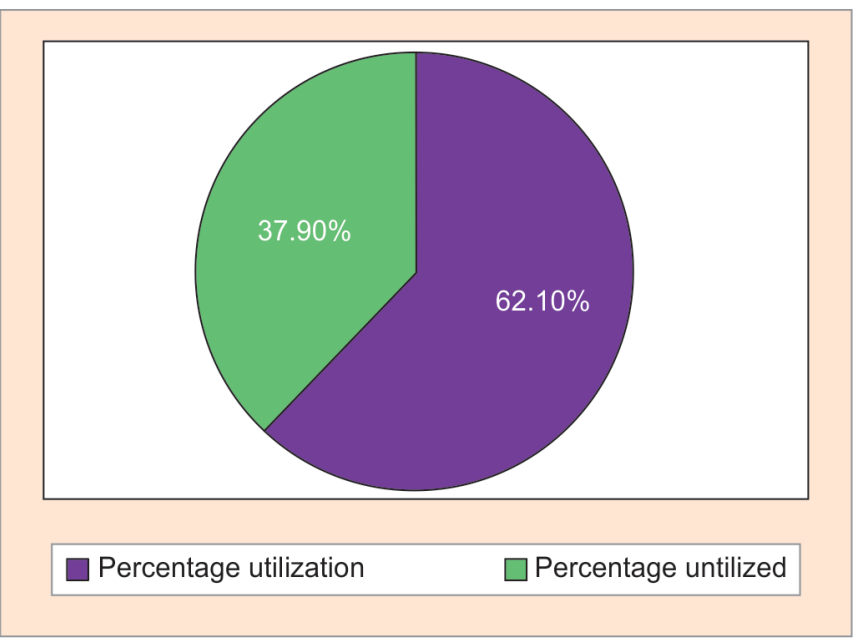

Graph 3: Average utilization coefficients of medium cost medical equipments

$60.2 \%$ (above $50 \%$ ). This figure reflects that the budget spent on average medical diagnostic equipment in this department is very much justifiable.

The study also showed that the cost incurred on various cost categories of diagnostic equipments, i.e. the low, medium and high cost equipments was also equally important since each category of medical equipment was used to an equal potential.

\section{ACKNOWLEDGMENT}

We would like to acknowledge the unconditional support and patience of our friend, Mrs Adarsh Bala, Assistant Librarian, GMCH, Chandigarh, who has spent hours with us in preparing the manuscript other than providing the relevant literature. We also thank the entire faculty and staff members of Histopathology Department, PGIMER, Chandigarh for their persistent support.

\section{REFERENCES}

1. Introduction to Management II: Essentials of Logistics and Equipment Management. New Delhi: IGNOU School of Health Sciences, 2010. p. 45.

2. Rajpal AS. Future trends in healthcare Industry in India. Express Healthcare. (Anniversary Edition).

3. Lathwal OP, Banerjee A. Availability and utilization of major Equipment at District Hospital Gurgaon, Haryana. J Acad Hosp Admn 2001;13(2).

4. Introduction to Management II: Practical Manual. New Delhi: IGNOU School of Health Sciences, 2010. p. 41-42.

5. Introduction to Management II: Essentials of Logistics and Equipment Management. New Delhi: IGNOU School of Health Sciences, 2010. p. 46-48.

6. Anand TR, Aggarwal AK. Guidelines for Equipments for Hospital of Different Sizes. New Delhi: National Institute of Health and Family Welfare, 1992. p. 9-13. 